\title{
Clinical review of pulmonary disease caused by Mycobacterium xenopi
}

\author{
MJ SMITH, KM CITRON \\ From the Cardiothoracic Institute, Brompton Hospital, London
}

ABSTRACT Mycobacterium xenopi comprised $56 \%$ of all non-tuberculous mycobacteria isolated in the Brompton Hospital laboratory during six years. $M$ xenopi alone was cultured from the sputum of 23 patients, whose clinical and bacteriological features are reviewed. Pulmonary disease was considered to be due to the organism present in 15 of these patients on the basis of strict criteria for a causal relationship. Radiographs of all these patients were consistent with mycobacterial disease, showing pulmonary cavitation in 11, apical shadowing in three, and upper lobe fibrosis in one. In nine patients the disease was chronic, progressing very slowly with longstanding respiratory symptoms and extensive radiographic abnormalities developing over many years (mean 19 years). In six patients the disease was subacute, being of recent onset with radiographic shadowing of limited extent. $M$ xenopi was isolated as a saprophyte from four patients who had lung disease of known cause and single isolates were obtained from four patients who had no lung disease attributable to this organism. In vitro drug sensitivity tests showed the sputum cultures of 17 of 22 patients to be sensitive to two or more of the drugs rifampicin, isoniazid, and ethambutol. Response to chemotherapy was unpredictable and did not always correlate with the results of sensitivity tests. Of 11 patients treated with at least two drugs to which their organisms were sensitive, two remained sputum positive, one relapsed after 18 months of chemotherapy, and eight have remained sputum negative during a minimum of three years' follow-up.

Mycobacterium xenopi was first isolated by Schwabacher in $1959^{1}$ from a cutaneous lesion of a South African toad, Xenopus laevis. The organism is a non-chromogenic acid-fast bacillus (Runyon group III) and its bacteriological characteristics have been well defined. ${ }^{2}$ The role of this organism as a cause of pulmonary disease is not well established. Strains of $M$ xenopi have been isolated from the sputum of patients in many parts of the world but only 50 cases have been reported in whom pulmonary disease has been ascribed to it. ${ }^{3}$ We have reviewed the records of patients from whose sputum $M$ xenopi was grown in the Brompton Hospital laboratory to determine whether their pulmonary disease could be attributed to this organism. Details of their clinical and bacteriological features and response to treatment are presented.

Address for reprint requests: Dr MJ Smith, Cardiothoracic Institute, Brompton Hospital, London SW3 6HP.

Accepted 10 January 1983

\section{Methods}

During the six years 1972-8 non-tuberculous mycobacteria were isolated from the sputum of 48 patients and $M$ xenopi was found in 27 (56\%) of them (table 1). This paper is concerned only with the 23 patients whose sputum contained $M$ xenopi alone. Identification of the organism and sensitivity testing were performed by the standard techniques used in our laboratory. ${ }^{4}$

\section{Results}

Radiology

All 23 patients had abnormal chest radiographs.

Table 1 Mycobacterial isolations $1972-8$

\begin{tabular}{lr}
\hline M tuberculosis & 1452 \\
$M$ xenopi alone & 23 \\
$M$ xenopi and $M$ tuberculosis & 3 \\
$M$ xenopi and $M$ kansasii & 1 \\
$M$ kansasii & 19 \\
\end{tabular}


Pulmonary cavitation was present in 14 , apical infiltration in four, right mid-zone shadowing in one, large bilateral bullae in one, pleural thickening in two, and a contracted fibrosed right upper lobe in one.

\section{Clinical features}

The symptoms described at the time of isolation of $M$ xenopi were as follows: cough in 22 patients, increase in dyspnoea in eight, haemoptysis in five, and chest pain in two. A few patients also presented with general symptoms of fever, malaise, or weight loss. Most patients had experienced an increase in symptoms before the isolation of the organism.

Various respiratory diseases had been diagnosed before the isolation of $M$ xenopi. Bacteriologically confirmed recurrent pulmonary tuberculosis had occurred in two patients and suspected but unconfirmed pulmonary tuberculosis in another two. Three patients had asthma, three unexplained pleural effusions, four chronic bronchitis, one extrinsic allergic alveolitis, and one invasive bronchopulmonary aspergillosis; and one had had a previous left upper lobectomy for adenocarcinoma of the lung. One other patient had developed a malabsorption syndrome after a partial gastrectomy. The remaining five patients had no previous history of chest disease or other significant illness.

\section{Bacteriology}

Of the 23 patients there were 17 who had $M$ xenopi cultured from multiple sputum samples, while in six it was present in only one of several samples. Drug sensitivities were available from 22 of the patients. Fifteen $(68 \%)$ were sensitive to rifampicin, 16 (73\%) to ethambutol, $13(59 \%)$ to isoniazid, and 17 $(77 \%)$ to streptomycin. Seven patients had sputum cultures sensitive to rifampicin, ethambutol, and isoniazid; 10 patients were sensitive to two of these drugs, and four to one of them, and a single patient was resistant to all three drugs.

\section{Role of $M$ xenopi in the patient's illness}

The 23 patients were divided into those thought to have pulmonary disease due to $M$ xenopi and those for whom there was no evidence that their pulmonary disease was due to the organism. The distinction was made on the basis of a combination of the following criteria: (1) the appearance of new symptoms or change in existing symptoms in relation to the first isolation of $M$ xenopi; (2) an abnormal chest radiograph consistent with mycobacterial infection; (3) the absence of pathogens other than $M$ xenopi in the sputum; (4) the absence of other diseases which might account for the patient's illness.

\section{Disease attributable to $M$ xenopi}

Fifteen patients fulfilled our criteria for diagnosing disease due to this organism. All had radiographic appearances consistent with mycobacterial disease (11 with cavitation) and new symptoms or exacerbations of chronic symptoms had occurred shortly

Table 2 Clinical and radiological features of 15 patients considered to have pulmonary infection due to Mycobacterium xenopi

\begin{tabular}{|c|c|c|c|c|}
\hline \multirow[t]{2}{*}{ Age (y) } & \multirow[t]{2}{*}{ Sex } & \multirow{2}{*}{$\begin{array}{l}\text { Radiographic abnormality at } \\
\text { presentation }\end{array}$} & \multicolumn{2}{|l|}{ Chest disease } \\
\hline & & & History . & Duration (y) \\
\hline \multicolumn{5}{|c|}{ Chronic disease } \\
\hline 77 & $\mathbf{F}$ & $\begin{array}{l}\text { Cavitation and contraction RUL } \\
\text { pleural thickening }\end{array}$ & $\begin{array}{l}\text { Pleural effusion, RUL } \\
\text { cavity }\end{array}$ & 17 \\
\hline 61 & $\mathbf{M}$ & $\begin{array}{l}\text { Multiple cavities LỦZ, LMZ } \\
\text { bilateral shadowing }\end{array}$ & Chronic cough, dyspnoea & 31 \\
\hline 70 & $\mathbf{M}$ & Multiple cavities LUL, pleural thickening & $\begin{array}{l}\text { Pleural effusion, apical } \\
\text { infiltration }\end{array}$ & 33 \\
\hline 59 & $\mathbf{M}$ & $\begin{array}{l}\text { Contracted, fibrosed LUL, bilateral } \\
\text { pleural calcification }\end{array}$ & $\left.\begin{array}{l}\text { ?Tuberculosis } 1946 \\
\text { ?Tuberculosis } 1960\end{array}\right\}$ no organisms & 30 \\
\hline $\begin{array}{l}73 \\
74\end{array}$ & $\begin{array}{l}\mathbf{M} \\
\mathbf{M}\end{array}$ & $\begin{array}{l}\text { Bilateral multiple cavities } \\
\text { Multiple bilateral apical cavities } \\
\text { extensive bilateral fibrosis }\end{array}$ & $\begin{array}{l}\text { Chronic cough, dyspnoea, malaise } \\
\text { ?Tuberculosis } 1966 \text {, no organisms }\end{array}$ & $\begin{array}{r}9 \\
10\end{array}$ \\
\hline 78 & $\mathbf{M}$ & $\begin{array}{l}\text { Multiple LUL cavities, extensive } \\
\text { shadowing LLL }\end{array}$ & Pleural effusion, apical infiltration & 18 \\
\hline $\begin{array}{l}78 \\
57\end{array}$ & $\begin{array}{l}\mathbf{M} \\
\mathbf{M}\end{array}$ & $\begin{array}{l}\text { Bilateral apical fibrosis, LUL cavity } \\
\text { Large cavity LUZ, mottled shadowing RUL }\end{array}$ & $\begin{array}{l}\text { Apical bullae, haemoptysis } \\
\text { L upper lobectomy, adenocarcinoma } \\
\text { of lung }\end{array}$ & $\begin{array}{r}15 \\
6\end{array}$ \\
\hline \multicolumn{2}{|c|}{ Subacute disease } & & & \\
\hline $\begin{array}{l}65 \\
52 \\
36 \\
67 \\
53 \\
24\end{array}$ & $\begin{array}{l}\mathbf{M} \\
\mathbf{M} \\
\mathbf{M} \\
\mathbf{M} \\
\mathbf{M} \\
\mathbf{F}\end{array}$ & $\begin{array}{l}\text { R apical shadowing } \\
\text { Multiple cavities LUL } \\
\text { RUL cavity and shadowing } \\
\text { R apical shadowing } \\
\text { LUL cavitation } \\
\text { L apical shadowing }\end{array}$ & $\begin{array}{l}\text { Asthma } \\
\text { Asthma } \\
\text { Nil } \\
\text { Nil } \\
\text { Nil } \\
\text { Nil }\end{array}$ & $\begin{array}{l}15 \\
10\end{array}$ \\
\hline
\end{tabular}

R-right; L—left; UL—upper lobe; LL—lower lobe; MZ—mid zone; UZ-upper zone. 
before the isolation of $M$ xenopi. Multiple sputum cultures were positive in 13 patients and there were single positive cultures among several negative cultures in two patients. The radiographic abnormalities in the latter two patients (left upper lobe infiltration and multiple cavities in one and right apical infiltration in the other) had progressed recently and $M$ xenopi was thought therefore to be causally related to the illness. Detailed investigation of these patients showed evidence of no other disease which might account for their illness. Contact tracing did not reveal any similar disease within their families.

On the basis of the history these 15 patients appeared to fall into two groups: a chronic disease group comprising nine patients with a very long history of respiratory symptoms and a subacute disease group of six patients with a much shorter history of respiratory symptoms. Details of these two groups are shown in table 2 .

\section{Chronic disease}

A long history of respiratory symptoms occurred in nine patients, of whom eight were men (mean age 69 years, range 59-78). Symptoms were longstanding, comprising cough, sputum production, and dyspnoea on effort. Unexplained pleural effusion had occurred in three patients and haemoptysis in three. All had extensive radiographic abnormalities, which had been developing over an exceedingly long time (mean duration 19 years, range 7-33) (table 2). All had upper lobe shadowing, which was bilateral in six patients, with cavitation in all but one; and many had radiographic evidence of longstanding fibrosis.

\section{Subacute disease}

A short history of respiratory symptoms occurred in six patients, of whom five were men (mean age 49 years, range 24-67). There was no previous history of respiratory symptoms in four and the other two patients suffered from asthma. The mean duration of presenting symptoms was 2.5 months and the radiographic abnormalities were not as extensive as in the chronic group. All six had unilateral upper lobe shadowing, which was cavitated in three (table 2). Two patients had had previous chest radiographs, which showed the shadowing to have developed within three and four months respectively.

\section{Disease not attributable to $M$ xenopi}

In eight patients there was no evidence that their pulmonary disease was causally related to $M$ xenopi. Four of these patients had a confirmed cause of their pulmonary disease-namely, bacteriologically confirmed recurrent pulmonary tuberculosis in two, extrinsic allergic alveolitis in one, and invasive bronchopulmonary aspergillosis in one. All four patients had multiple isolations of $M$ xenopi and three had received antituberculous chemotherapy after the isolation of the organism. In none of them, however, did this appear to alter the clinical picture or the radiograph. The fourth patient did not receive chemotherapy and $M$ xenopi subsequently cleared spontaneously from the sputum.

The remaining four patients had minor radiographic abnormalities, with pleural thickening in two of them, a small area of infiltration (which was longstanding) in one, and a small patch of consolidation which resolved spontaneously in the final patient. All had only single isolations of $M$ xenopi from several sputum samples.

\section{Response to chemotherapy}

Details of treatment, drug sensitivities, and response to chemotherapy in 11 of the patients considered to have pulmonary disease due to $M$ xenopi are shown in table 3. Nine patients received chemotherapy

Table 3 Treatment, drug resistance, and response in 11 patients with pulmonary disease due to Mycobacterium xenopi

\begin{tabular}{|c|c|c|c|c|}
\hline Patient No. & Drugs given & $\begin{array}{l}\text { Duration of treatment } \\
(m)\end{array}$ & $\begin{array}{l}\text { Drug resistance }(R) \\
\text { and sensitivity }\end{array}$ & Response \\
\hline $\begin{array}{l}1 \\
2\end{array}$ & $\begin{array}{l}\text { Rifampicin, isoniazid, aminosalicylic acid (PAS) } \\
\text { Rifampicin, ethambutol, isoniazid }\end{array}$ & $\begin{array}{l}24 \\
18\end{array}$ & $\begin{array}{l}\mathbf{R} \text { to ethambutol } \\
\text { Fully sensitive }\end{array}$ & $\begin{array}{l}\text { Cure } \\
\text { Relapse } \\
\text { after } 1 \text { y }\end{array}$ \\
\hline $\begin{array}{l}3 \\
4 \\
5\end{array}$ & $\begin{array}{l}\text { Rifampicin, ethambutol, isoniazid } \\
\text { Surgical resection, ethambutol } \\
\text { Rifampicin, ethambutol, isoniazid } \\
\text { then ethambutol, prothionamide }\end{array}$ & $\begin{array}{r}18 \\
12 \\
3 \\
21\end{array}$ & $\begin{array}{l}\text { Fully sensitive } \\
\mathbf{R} \text { to isoniazid } \\
\mathbf{R} \text { to rifampicine, } \\
\text { isoniazid }\end{array}$ & $\begin{array}{l}\text { Cure } \\
\text { Cure } \\
\text { Cure }\end{array}$ \\
\hline 6 & $\begin{array}{l}\text { Rifampicin, ethambutol, isoniazid } \\
\text { Rifampicin, ethambutol, isoniazid, streptomycin } \\
\text { then streptomycin, ethionamide, isoniazid }\end{array}$ & $\begin{array}{l}8 \\
6 \\
\text { until death }\end{array}$ & $\begin{array}{l}\mathbf{R} \text { to isoniazid } \\
\text { Fully sensitive }\end{array}$ & $\begin{array}{l}\text { Cure } \\
\text { No response } \\
\text { Sputum positive }\end{array}$ \\
\hline 8 & $\begin{array}{l}\text { Rifampicin, ethambutol, then prothionamide, } \\
\text { cycloserine, capreomycin, isoniazid }\end{array}$ & $\begin{array}{r}5 \\
15\end{array}$ & $\mathbf{R}$ to rifampicine & $\begin{array}{l}\text { No response } \\
\text { Sputum positive }\end{array}$ \\
\hline 9 & Rifampicine, ethambutol, isoniazid & 18 & $\mathbf{R}$ to isoniazid & Cure \\
\hline 10 & Ethambutol, isoniazid & 17 & Fully sensitive & Cure \\
\hline 11 & Rifampicin, ethambutol, isoniazid & 18 & $\mathbf{R}$ to ethambutol & Cure \\
\hline
\end{tabular}


with at least two drugs to which their organism was sensitive in vitro and all achieved sputum conversion with clinical and radiographic improvement. All have been followed up for a minimum of three years. Bacteriological relapse occurred in one patient one year after stopping an 18-month course of chemotherapy with drugs to which the organism was fully sensitive. There were two patients in whom chemotherapy was unsuccessful and who remained sputum positive throughout their treatment. The first patient presented with very extensive disease and was initially treated with rifampicin, ethambutol, isoniazid, and streptomycin. The organism was fully sensitive in vitro but the patient remained positive on sputum culture and treatment was stopped after six months. The patient continued to deteriorate and, after a further six months, treatment was restarted with streptomycin, isoniazid, and ethionamide. The patient died, however, three months later. The second patient had received rifampicin, isoniazid, and ethambutol although the organism in this case was resistant in vitro to rifampicin. There was no response to treatment and after five months the regimen was changed to prothionamide, cycloserine, capreomycin, and isoniazid. The sputum remained positive on culture at the last follow-up visit.

\section{Discussion}

Determining the clinical significance of $M$ xenopi in the sputum of a patient is difficult. There are no simple diagnostic features which discriminate between disease due to this organism and other chest disease with saprophytic colonisation by the organism. The occurrence of two or more positive cultures as a single criterion is not, in our view, satisfactory and we describe here two patients who had disease thought to be attributable to $M$ xenopi from whom only single positive cultures were obtained. We have suggested four criteria (see above) for establishing a causal relationship between the isolation of $M$ xenopi and pulmonary disease. We divided our patients with disease due to this organism into chronic and subacute groups on the basis of the history. Those with chronic disease had exceedingly long histories, progressive pulmonary damage, and longstanding extensive radiographic abnormalities. In the absence of any other cause of their disease $M$ $x e n o p i$ infection seems likely to have been present for many years either as a continuous low-grade infection, a relapsing infection, or (perhaps less likely) a recurrent reinfection. The subacute group had much shorter illnesses and less extensive radiographic changes.

The epidemiology of $M$ xenopi has some unusual features. In Britain most isolations occur in Southeast England, particularly in coastal regions and around estuaries. Because of this distribution and a moderate degree of pathogenicity for fow ${ }^{256}$ it has been suggested that the organism may normally live as a commensal or pathogen in sea birds. There is evidence of contamination of water supplies by $M$ xenopi $i^{78}$ and hospital-acquired infection has been described in which $M$ xenopi was found in the hot water generators. ${ }^{9} M$ xenopi is one of the few nontuberculous mycobacteria for which cases of possible person-to-person infection have been described, ${ }^{510}$ though these infections occurred in close relatives who were presumably sharing the same environment. No obvious factors predisposing to infection were found in our group except in two patients whose radiographs showed upper zone vascular attenuation. Radiographic evidence of emphysema was said to be present in 11 of 14 patients with hospital-acquired infection with $M$ xenopi reported from the United States. ${ }^{9}$

Non-tuberculous mycobacteria are often found to be resistant in the in vitro laboratory sensitivity tests according to the criteria of resistance considered to be significant in the treatment of tuberculosis. The results of chemotherapy for non-tuberculous mycobacterial infection may not, however, reflect the results of sensitivity tests. In a recent report of pulmonary infection due to the $M$ aviumintracellulare complex in Britain ${ }^{11}$ good results were achieved with standard first-line antituberculous drugs despite in vitro resistance in some cases. $M$ xenopi is relatively sensitive to antituberculous drugs in vitro ${ }^{12}{ }^{13}$ but information about response to chemotherapy is lacking. In our series 17 of the 22 patients with sensitivity results had sputum cultures sensitive to at least two of the drugs rifampicin, ethambutol, and isoniazid. Sputum conversion was achieved in nine of the 11 patients treated $(82 \%)$ and in all nine patients the chemotherapy regimen included at least two drugs to which the organism was sensitive. One patient, however, relapsed and two failed to respond despite having drugs to which the organisms were sensitive in vitro. Our experience therefore suggests that while in vitro drug resistance is not a major problem with this organism the clinical response is unpredictable. With one exception the patients received chemotherapy for at least 18 months and, in the absence of information about the efficacy of chemotherapy of shorter duration, it would seem reasonable to recommend a treatment period of 18-24 months.

It would be difficult to obtain enough patients for a prospective trial of chemotherapy in this rare disease. It is therefore important that as much information as possible is collected about the clinical fea- 
tures and treatment of these infections so that a more rational approach to diagnosis and management may be developed.

We would like to thank the physicians at the Brompton Hospital and London Chest Hospital for allowing us access to their patients' notes and radiographs and to Mrs MV Chadwick for supplying the bacteriological data.

\section{References}

${ }^{1}$ Schwabacher H. A strain of mycobacterium from skin lesions of a cold blooded animal Xenopus laevis, and its relation to atypical acid fast bacilli occurring in man. J Hyg (Lond) 1959;57:57-67.

${ }^{2}$ Stanford JL, Grange JM. The meaning and structure of species as applied to mycobacteria. Tubercle 1974;55:143-52.

${ }^{3}$ Wolinsky E. Non-tuberculous mycobacteria and associated diseases. Am Rev Respir Dis 1979;119:107-59.

${ }^{4}$ Chadwick MV. Mycobacteria. 1st ed. London: PSG Wright, 1981:61-100.

${ }^{5}$ Boisvert H. Mycobacterium xenopei (Marks and Schwabacher, 1965). Mycobacterie scotochromogène, thermophile, dysgonique, eventuellement pathogène pour l'homme. Ann Inst Past (Paris) 1965;109:447-53.

${ }^{6}$ Engbaek HC, Vergmann B, Baess I, Will DW. $M$ xenopei: a bacteriological study of $M$ xenopei, including case reports of Danish patients. Acta Pathol Microbiol Scand (Kobenhavn) 1967;69:577-94.

${ }^{7}$ McSwiggan DA, Collins $\mathbf{C H}$. The isolation of $M$ kansasii and $M$ xenopi from water systems. Tubercle (Lond) 1974;55:291-7.

${ }^{8}$ Goslee S, Wolinsky E. Water as a source of potentially pathogenic mycobacteria. Am Rev Respir Dis 1976;113:287-92.

9 Costrini A, D'Escopo N, Gross W, Hawkins J. Clinical and roentgraphic features of nosocomial infection due to Mycobacterium xenopi (abstract from American Thoracic Society Meeting, 1978). Am Rev Respir Dis 1978;117:suppl 4, 418.

${ }^{10}$ Beck A, Keeping JA, Zorab PA. Anonymous mycobacteria in man and wife. Tubercle (Lond) 1963;44:378-80.

"Hunter AM, Campbell IA, Jenkins PA, Smith AP. Treatment of pulmonary infections caused by mycobacteria of the Mycobacterium avium intracellulare complex. Thorax 1981;36:326-9.

${ }_{12}$ Marks J, Schwabacher H. Infection due to Mycobacterium xenopei. Br Med J 1965;i:32-3.

${ }^{13}$ Beck A, Stanford JL. Mycobacterium xenopei: a study of sixteen strains. Tubercle (Lond) 1968;49:226-34. 